\title{
Students' Readiness towards M-Learning: A Case Study of Pre-Service Teachers in Palestine
}

\author{
Ali Zuhdi Shaqour \\ An Najah National University \\ E-mail: zuhdi4@najah.edu
}

\section{Doi:10.5901/jesr.2014.v4n6p19}

\section{Abstract}

This study examines pre-service teachers' (PST) attitudes towards, readiness to use and the nature of usage of mobile technologies. The main objective of the study is to explore the different aspects of M-devices in terms of the actual use, attitudes of use and willingness to use in learning context of PST in College of Education and Teacher Preparation (CETP) at An Najah National University (NNU) in Palestine. The results of the study could inform NNU administrators and faculty members about the possibilities of integrating M-devices in the teaching/learning process. Data was obtained from a sample of 71 PSTs enrolled in "Computers in Education" course in the second semester of 2013/2014 academic year. The results revealed that many PSTs owned one or more mobile devices. For most students, the use of mobile devices is a routine part of their own lives with limited placement in their educational environment. Data suggest that NNU administration and PSTS teachers need to consider the availability of $M$-devices in the hands of students and to explore these emerging technologies for teaching. The results of this study can be used to inform NNU and other institutions the capabilities and willingness of students to use mobile devices in their learning.

Keywords: Higher education; Improving teaching/learning; M-learning; technology integration

\section{Introduction}

Mobile devices, handheld computing devices and tablet devices are some of the electronic devices that emerged in the early 1980s as a result of the advancement of both communications and technology fields. These devices are "...designed to be extremely portable, often fitting in the palm of your hand or in your pocket. ... they allow you to do many of the same things you can do with a desktop or laptop computer. (Computer Basics, getting to know mobile devices)". Embedded virtual keyboards with a touch-screen are common features of these devices Such facilities are the main input instruments which users of these devices use to perform tasks like browsing the web, playing games, watching videos, reading e-books and communicating synchronously and asynchronously through text, voice or video.

The role of mobile devices in education, an emerging field, has increased in popularity in the field of educational research. Several international conferences, summits and symposia were conducted in different parts of the world during the past few years to discuss and activate these devices in learning worldwide. Among these events are;

- In August 2011 the first m4Ed4Dev symposium convened by United States Agency for International Development (USAID) in Washington D.C. as a prelude to launching the mEducation Alliance in early 2012.

- In November 2011, World Innovation Summit for Education (WISE), an annual educational convention funded by the Qatar Foundation, focused on mobiles,, education and the hard-to-reach.

- In December 2011, , the United Nations Educational, Scientific and Cultural Organization UNESCO, convened its First Mobile Learning Week in Paris

- In September 2012, The next mEducation Alliance Symposium, entitled Partnering For Scale And Impact, illustrated the growing emphasis and direction of both corporate and agency priorities.

- In February 2013, the second UNESCO event, another Symposium, included in its Mobile Learning Week, in Paris, shared with USAID, and focused on three particular Education For All (EFA), goals which are relate to mobile learning, namely: Mobiles for Literacy, Mobiles for Quality of Education and Mobiles for Gender Equality. (Traxler, 2013).

Education has benefited from services offered by the fast growing sector of mobile devices' platforms and software. This resulted in the appearance of new emerging field on the scene called mobile learning. Sampson \& Zervas (2013), indicated four promises could be offered by these devices; 
"(a) engage students to experiential and situated learning without place, time and device restrictions, (b) enable students to continue learning activities, initiated inside the traditional classroom, outside the classroom through their constant and contextual interaction and communication with their classmates and/or their tutors, (c) support on-demand access to educational resources regardless of students' location or device used and (d) extend traditional teacher-led classroom scenario with informal learning activities performed outside the classroom." (2013).

The reason behind this considerable interest in mobile learning is due to the potentiality of this approach of learning in terms of its effect on learners, their teachers and the institutions (Traxler, 2012; World Bank, 2011; Kissinger, 2013; Sampson \& Zervas, 2013 ). According to Traxler "Mobile learning as a concept and as a community have been successful in many respects working within educational institutions to extend the reach of education, to enrich its experience, to motivate learners and to extend educational theory." (2012).

In the domain oflearning there are many leading determinants to achieving the desired learning outcomes which is the true indicator to the success or failure of educational institutions. Among these determinants are; teaching methods and strategies, learners' needs and their differences, the learning environment itself...etc. Garris, et al. (2002), claimed that "... recent research has begun to establish links between instructional strategies, motivational processes, and learning outcomes". Students' motivation should be highly considered, among other determinants by teachers because it is the primary force responsible for enhancing or hindering their learning. As stressed by Odera, (2011), "Teachers need to employ motivational strategies in the classroom to try to arouse learners' curiosity and sustain their interest throughout the lesson". Such strategies were defined by Naismith and his colleagues (2004), when they categorized learning activities that are possible in mobile learning setting. These activities are;

1. activities that promote learning as a change in learners' observable actions

2. activities in which learners actively construct new ideas or concepts based on both their previous and current knowledge

2. activities that promote learning within an authentic context and culture;

1. activities that support learning outside a dedicated learning environment and formal curriculum

2. activities that promote learning through social interaction

3. activities that assist in the coordination of learners and resources for learning activities

The above mentioned activities are informed by the dominant constructivist learning theory and its social constructivism approach. They also promote learner centeredness in which learners become the focus of the teaching/learning process.

Today, mobile devices are one of the leading innovative technological tools of communication and are considered a part of the lives of the young generation including students. The widespread use of these devices among them is due to many reasons illustrated by Cook (2010), "...the increasing portability and functional convergence of technologies, as well as the reduction in their cost, and the cost of services available for them, mobile devices have become more and more central to, and at the same time invisible in the life-worlds of users." Cook (2010), "argued that the context for learning in the 21st Century is being augmented and accelerated by new digital tools and media, particularly by mobile devices and the networks and structures to which they connect people."

This current study tries to examine the readiness of PSTs at CETP in using mobile devices in their learning practices to better their performances. Many researchers found that students' perceptions, attitudes and actual use of technology are important for motivating them to learn. McAndrew, \& Clough (2006), argued that "it is important to understand learners' previous and current use of technologies and the wider context in order to start to unravel what might motivate them in using mobile devices for their learning". The main concern of this study was to assess mobile devices use among PST at CETP and to find out their awareness of this kind of technology.

\subsection{Study context}

An Najah National University (NNU), as one of the leading higher education institutions in Palestine, is working hard to remain in the lead of other institutions in Palestine and to advance its rank among other Arab higher education institutions. "The University has received several significant recognitions and rankings. It was ranked first among Palestinian universities, sixth among Arab universities, and in the top $4 \%$ of universities evaluated worldwide, according to Webometrics measures and international classifications of the Webometrics website. "...An-Najah constantly strives to better its academic offerings and to improve its PST' educational experience" (NNU welcome message of the president). Among other efforts, NNU administration is doing its best to integrate technology in the teaching/learning process for quality assurance. Zajel, NNU's administrative platform and Moodle learning management system are two examples of 
this integration. Internet wired and wireless connections are available for teachers and students within NNU campuses In addition to other hardware and software facilities, computer labs with internet connection are also available for these teachers and students.

In spite of the above, mobile learning approach is still in its infancy at NNU and it is not yet considered officially as a means to facilitate the teaching/learning process. The potentiality and effectiveness of this approach encouraged the researcher to uncover it at NNU through exploring the views towards, awareness and usage of mobile devices among PSTs. The results of the study might inform NNU administrators to help adopting this new technology in the university practices. It might also encourage other teachers to research mobile learning theoretically and practically.

The results of this study might also benefit the teachers through encouraging them to use mobile devices in their practices when recognizing the availability and use of these devices among their PSTs. This leads the teachers to explore and test new and unconventional teaching methods and strategies which might help in developing their professions.

\subsection{Limitations}

Current study examined only PSTs from CETP at NNU which limits the results to this population. Students from other colleges and departments might generate different results about mobile devices. In spite of this, the study is considered the first to explore the use of mobile devices at NNU in order to pave the road in front of other researchers and teachers to research and test the potential of these devices in the teaching/learning process.

\subsection{Study questions}

This current study was designed to examine the following questions:

What is the current situation of PSTs concerning the availability of mobile devices among them?

How do PSTs use mobile devices?

Do PSTs hold positive attitudes towards using mobile devices in their learning process?

\section{Methodology}

\subsection{Participants}

The participants of this study were 112 PSTs registered in the second semester of 2013/2014 academic year studying "Computers in Education" This course is a compulsory course and students enrolled in it were from all CETP programs.

\subsection{Instrument}

A survey instrument was developed by the researcher after reviewing related works, i.e. Kissinger (2013), McAndrew \& Clough (2006), Lee, Cheung \& Chen (2005). The survey was pilot-tested by a group of PTs and then revised accordingly. 112 instruments were distributed to all CE students enrolled in the second semester of 2013/2014 academic year. The number of returned instruments were 71 for a rate of about $63 \%$.

The survey consisted of 16 questions focusing on the ownership of mobile devices, students' usage, their views towards using these devices in their study programs and the facilities available for using mobile devices.

Because of the nature of the quantitative data obtained by the survey, the common analysis method used in this study was descriptive statistics which included the numbers of frequencies and percentages. The analysis was achieved through SPSS software. Data obtained assisted the researcher to answer the study questions.

\section{Results and discussion}

The following paragraphs analyses PSTs responses to the survey items in order to answer the study questions.

\subsection{Availability of mobile devices:}

The first question tried to determine the current situation of PSTs concerning the availability of mobile devices. To 
determine this; three sub questions cover the availability of mobile devices as the following:

Current situation of ownership of mobile devices among PST: results.

To answer this question, the researcher computed the frequencies and the percentages, and table 1 shows the

Table 1: Mobile Devices among PST

\begin{tabular}{|c|c|c|}
\hline Ownership & Frequency & Percentage \\
\hline Yes & 70 & 98.6 \\
\hline No & 1 & 1.4 \\
\hline Total & 71 & 100 \\
\hline
\end{tabular}

As shown in table 1, about $99 \%$ of the participants have mobile devices. This indicates that almost all students own such devices.

\subsection{Type of mobile devices among PST:}

To answer this question, the researcher computed the frequencies and the percentages of PSTs responses to the item related to their device type ownership, and table 2 shows the results.

Table 2: type of Mobile Devices among PST

\begin{tabular}{|l|c|c|}
\hline Type & Frequency & Percentage \\
\hline Mobile Phone & 35 & 49.3 \\
\hline Laptop & 12 & 16.9 \\
\hline iPad & 0 & 0 \\
\hline Mobile Phone \&Laptop & 24 & 33.8 \\
\hline All Devices & 0 & 0 \\
\hline Total & 71 & 100 \\
\hline
\end{tabular}

As shown in table 2, about $49 \%$ of the participants have only a mobile phone, about $17 \%$ have only laptops, and about $34 \%$ have a mobile phone and laptop, which is about one third of the population, while iPad is not common among these students. As mobile phones and laptops have many applications in common i.e. cloud applications like DropBox, Google apps. there will be no problem in using those two types of devices in teaching/learning process, students could access the applications from both types.

\subsection{Financial burden of mobile devices ownership:}

To answer this question, the researcher computed the frequencies and the percentages of the item asking if the ownership of mobile devices consequents any financial burdens, and table 3 shows the results.

Table 3: Financial Burden of Mobile Devices Ownership

\begin{tabular}{ccc}
\hline Financial Burden & Frequency & Percentage \\
\hline Yes & 17 & 23.9 \\
No & 54 & 76.1 \\
Total & 71 & 100 \\
\hline
\end{tabular}

As shown in table 3 , about $76 \%$ of the participants said that mobile devices do not cause financial burden. This is true as internet accessibility is available to participants (see table: 4 below) within the university borders free of charge and at home with a low cost. This is also another factor that could be consider to encourage the use of mobile devices at NNU. As discussed above, the availability of mobile devices among participants with no cause of financial burden indicates and asserts what Cook (2010), that these devices are becoming parts of learners' daily lives practices. Using these popular and "stimulated" devices in the learning process should be encouraged. 


\subsection{Nature of usage:}

The second question tried to explain how PSTs use mobile devices. For this, the survey consisted of items related to the nature of use of these devices among participants. The answers of the three items covered the manner of use are explained in the following tables.

\subsection{Internet access locations:}

The following frequencies and the percentages of table 4 illustrate locations were participants usually access the internet.

Table 4: internet access locations

\begin{tabular}{lcc}
\hline Internet Access Locations & Frequency & Percentage \\
\hline Home & 6 & 8.5 \\
University & 5 & 7 \\
Both & 60 & 84.5 \\
Total & 71 & 100 \\
\hline
\end{tabular}

As shown in table 4, all participants had access to the internet. The majority of them, about $85 \%$, could access the internet from their homes and the university. These results proves that accessing the internet is available among most participants and no serious obstacles that could hinder this accessibility.

\subsection{Internet access devices:}

In order to determine the type of devices participants use to access the internet, they were asked to identify these devices. Table 5 includes the frequencies and the percentages of the results.

Table 5: internet access devices

\begin{tabular}{lcc}
\hline Devices Internet Access & Frequency & Percentage \\
\hline Pc & 11 & 15.5 \\
Mobile Phone & 12 & 16.9 \\
Both of Them & 48 & 67.6 \\
Total & 71 & 100 \\
\hline
\end{tabular}

As shown in table 5, about $16 \%$ of the participants access the internet using Pcs, about $17 \%$ use their mobile phones and about $68 \%$ access the internet using both Pcs and mobile phones. These results also indicate that most of participants have the accessibility alternatives i.e. Pcs and mobile devices.

Difficulties of accessing the internet through mobile devices in university campus:

Participants were asked about the technical facilities offered by the university related to internet connectivity within the campus borders. Table 6 shows the frequencies and the percentages of these participants' answers.

Table 6: Difficulties of accessing the internet through mobile devices in university campus

\begin{tabular}{ccc}
\hline Difficulties of Using Mobile Devices & Frequency & Percentage \\
\hline Yes & 42 & 59.2 \\
No & 29 & 40.8 \\
Total & 71 & 100 \\
\hline
\end{tabular}

As shown in table 6 , about $59 \%$ of the participants said that, they have difficulty accessing the internet in university campuses, while about $41 \%$ of them didn't face difficulties in accessing the internet through their mobile devices. These difficulties are due to the limitation of internet coverage in certain areas within university campuses. 


\subsection{Usage related to learning}

The third question tried to identify the attitudes of PSTs towards using mobile devices in learning process. To answer that; three sub questions cover the attitudes of PSTs as the following:

Using mobile devices in learning process:

To identify participants' state of use of their mobile devices in learning, they were asked if they used them for that or not. The frequencies and the percentages of their answers were shown in table 7 below.

Table 7: Using Mobile Devices in Learning Process

\begin{tabular}{ccc}
\hline Learning Process & Frequency & Percentage \\
\hline Yes & 63 & 88.7 \\
No & 8 & 11.3 \\
Total & 71 & 100 \\
\hline
\end{tabular}

As shown in table 7, about $89 \%$ of the participants use mobile devices in learning process. This means that these participants are aware of the potentiality of these devices in their learning programs.

\subsection{Influence for using mobile devices in learning process:}

In order to know if their teachers had any influence in using mobile devices in their learning, participants were asked to verify if their use was self motivated or guided by their teachers. The following table shows the frequencies and percentages of their answers

Table 8: Influence for using mobile devices in the learning process

\begin{tabular}{ccc}
\hline Guide & Frequency & Percentage \\
\hline My-self & 59 & 83.1 \\
The teacher & 12 & 16.9 \\
Total & 71 & 100 \\
\hline
\end{tabular}

As shown in table 8 , about $83 \%$ of the participants use mobile devices in learning process through self motivation. The results of both table 7 and table 8 evidenced the enthusiasm and impulsion of the participants towards using these devices in their learning process. For this, faculty members should make use of this preferred strategy of learning in order to keep their learners motivated, curious and interested as Odera (2011), claimed.

\subsection{Preferences to use mobile devices in learning process by teaches :}

To answer this question, the researcher computed the frequencies and the percentages of participants' responses and table 9 shows the results.

Table 9: Preferences to Use Mobile Devices in Learning Process

\begin{tabular}{ccc}
\hline Preferences to Use Mobile Devices & Frequency & Percentage \\
\hline Yes & 63 & 88.7 \\
No & 8 & 11.3 \\
Total & 71 & 100 \\
\hline
\end{tabular}

As table 9 shows, about $89 \%$ of the participants preferred to use mobile devices in learning process by their teachers. This result reinforces what the previous two questions claimed.

Need for courses to develop skills in using mobile devices:

To answer this question, the researcher computed the frequencies and the percentages, and table 10 shows the results. 
Table 10: Need For Courses to Develop Skills in Using Mobile Devices

\begin{tabular}{ccc}
\hline Need For Courses & Frequency & Percentage \\
\hline Yes & 24 & 33.8 \\
No & 47 & 66.2 \\
Total & 71 & 100 \\
\hline
\end{tabular}

As shown in table 10, about $66 \%$ of the participants said they do not need courses to develop their skill in using mobile devices. The results might be an indicator to the nature of most available applications nowadays which tend to be user friendly.

\section{Conclusion and Recommendations}

This current study tried to examine the state of using mobile devices among university students in order to inform the university administration and its faculty members the levels of ownership and readiness of their students to use them in their learning programs. It also examined these students' willingness to use these devices and if they faced problems when using them within the campus borders. In addition, the study explored the role of their teachers, if any, in using these devices in their learning process.

The results clearly indicated almost all students owned mobile devices, that is $99 \%$ of participants. The results also showed that both mobile phones and laptops are owned by students. This ownership of those two types didn't affect the implementation of such devices in the learning process as most well known learning applications could work on both types such as Google apps., DropBox, Skype, Voice Thread and other educational applications. Another important result this study concluded was that students' use of mobile devices present an extra financial burden.

The study explored the nature of students' usage of their mobile devices and found out that they could access the internet from both home and the university; about $85 \%$ of respondents declared this. This shows that they face no problem in accessing the internet, which is crucial when thinking of mobile learning. Although $59 \%$ of student participants indicated that they faced difficulty in accessing the internet within the campus borders, $41 \%$ said they didn't face such difficulties.

$89 \%$ of participating students showed their awareness of using their devices in their learning process. This indicated their positive attitudes towards learning through mobiles, although the usage was not directed or led by their teachers. In addition, they liked their teacher to integrate these mobiles in their teaching process. Lastly, $34 \%$ of the student participants in this survey needed courses to develop their mobile technology skills

Finally, as to the knowledge of the researcher, this study was a first step in exploring NNU students' readiness of using mobile devices in their learning process, their attitudes towards using such devices and the possibilities of integrating these technologies in the teaching/learning process. Recommendations for future research might include:

- Conduct studies to explore the university's views towards integrating mobile devices in its practices.

- Conduct a study using other colleges and departments to explore their readiness to use mobile devices in their learning process.

- Conduct a study that involves faculty members to explore their readiness of using mobile devices in their teaching practices.

- Conduct follow-up studies to examine and explore the potentiality of mobile learning.

\section{References}

Cook, J. (2010). Mobile phones as mediating tools within augmented contexts for development. International journal of mobile and blended learning, 2(3), 1-12.

Garris, R., Ahlers, R., \& Driskell, E. (2002).Games, motivation, and learning: A research and practice model. Simulation \& gaming, 33(4), 441-467.

Goodwill Community Foundation (2014).Computer Basics, getting to know mobile devices. Retrieved Jan 21, 2014, from http://www.gcflearnfree.org/computerbasics/9/print

Kearney, M., \& Maher, D. (2013).Mobile learning in math's teacher education: Using iPad to support pre-service teachers' professional development. Australian Educational Computing, 27(3), 76-84.

Kearney, M., Schuck, S., Burden, K., \& Aubusson, P. (2012). Viewing mobile learning from a pedagogical perspective. Research in Learning Technology, 20(1), 1-16. 
Kissinger, J. S. (2013). The social and mobile learning experiences of students using mobile e-books. Journal of Asynchronous Learning Networks, 17(1), 153-169.

Lee, K., Cheung, M., \& Chen, Z. (2005).Acceptance of internet-based learning medium: The role of extrinsic and intrinsic motivation. Information \& management, 42(8), 1095-1104.

McAndrew, P., \& Clough, G. (2006). Affective factors in learning with mobile devices. Big Issues in Mobile Learning, 14.

Naismith, M. Sharples, G. Vavoula, G, \&Lonsdale, P. (2004).Literature review in mobile technologies and learning. Retrieved April 21, 2014, from http://telearn.archives-ouvertes.fr/docs/00/19/01/43/PDF/Naismith_2004.pdf

Odera, F. Y. (2011). Motivation: The most ignored factor in classroom instruction in Kenyan secondary schools. International Journal of Science and Technology, 1(6), 283-288.

Sampson, G., \& Zervas, P. (2013, February).Context Aware Adaptive and Personalized Mobile Learning. In 3rd international conference for e-learning \& distance education. Riyadh, Saudi Arabia.

Traxler, J. (2013). mLearning solutions for international development - rethinking the thinking. Digital Culture \& Education, 5:2, 74-85. Retrieved March 23, 2014, from http://www.digitalcultureandeducation.com/cms/wp-content/uploads/2013/12/traxler.pdf

World Bank (2011), Transformation-Ready: The strategic application of information and communication technologies in Africa Education Sector Study, Washington: World Bank with African Development Bank and the African Union, Retrieved April 15, 2014, from http://siteresources.worldbank.org/extinformationandcommunicationandtechnologies/resources/282822-

1346223280837/Education_Fullreport.pdf 